\title{
Epistemic Structural Realism and Poincaré's Philosophy of Science
}

\author{
Katherine Brading* and Elise M. Crull ${ }^{\dagger}$
}

Dec 2009; revised Aug 2010

\begin{abstract}
Recent discussions of structuralist approaches to scientific theories have stemmed primarily from Worrall's (1989), in which he defends a position (since characterized 'epistemic structural realism') whose historical roots he attributes to Poincaré. In the renewed debate inspired by Worrall, it is thus not uncommon to find Poincaré's name associated with various structuralist positions. However, Poincaré's structuralism is deeply entwined with both his conventionalism and his idealism, and in this paper we explore the nature of these dependencies. What comes out in the end is not only a clearer picture of Poincaré's position regarding structuralism, but also two arguments for versions of epistemic structuralism different in kind from that given by Worrall.
\end{abstract}

\section{Introduction}

In what has become the seminal realism paper in the literature - Worrall's (1989) - Worrall offers a middle ground for those who feel the realist pull of the "no-miracles" intuition whilst recognizing the anti-realist thrust of the argument based on the pessimistic meta-induction. Following Ladyman's (1998) distinction between ontic and epistemic approaches, Worrall's position has been further clarified and dubbed epistemic structural realism (hereafter ESR). In his work, Worrall appeals to Poincaré as a historical source for his position. The primary goal of the present paper is to clarify the extent to which (or, better: the senses in which) Poincaré's structuralism is appropriately labeled "epistemic" and "realist". Specifically, we explore the relationship between Poincaré's structuralism and his idealism and conventionalism. In the process, we come across two additional arguments for structuralism, different in kind from that offered by Worrall.

We begin, in section 2, with a brief review of Worrall's position and his appeal to Poincaré. This includes the first argument for structuralism-that offered by Worrall.

\footnotetext{
*Department of Philosophy, University of Notre Dame. Email: kbrading@nd.edu

${ }^{\dagger}$ Edelstein Center for History and Philosophy of Science, Technology \& Medicine, Hebrew University.

Email: elise.crull@gmail.com
} 
Section 3 offers some preliminary remarks on Poincaré's epistemology, structuralism and realism. These remarks provide a framework for our more detailed discussion, and are sufficient to lead us to the second argument for structuralism (see section 4). Our detailed discussion of Poincaré's discussion begins in section 5, with consideration of the role of Kantian idealism. This leads to the third argument for structuralism (given in section 6). Next, we consider the relevance of Poincaré's famous conventionalism for his characterization as an epistemic structural realist (section 7). We end with a discussion of the three arguments thus elaborated (section 8) and some concluding remarks (section 9). The upshot is, we hope, a clearer understanding of Poincaré's position with respect to the current structural realism debate. Specifically, we can see the similarities and differences between Poincaré's position and contemporary ESR in terms of the character of each, along with the arguments on which each is founded.

\section{Poincaré and Worrall's ESR}

The central thesis of Worrall's ESR is that we have good reason to believe that the entities in the world exemplify the structures posited by our best scientific theories, but we should be epistemically non-committal about the non-structural natures of the entities in question. Worrall writes $(1989$, p. 122, emphasis original): "[The structural realist] insists that it is a mistake to think that we can ever 'understand' the nature of the basic furniture of the universe." The position is thus presented as a retreat from full-blown scientific realism that reflects the epistemic modesty appropriate in light of the argument from the pessimistic meta-induction. Because the position was developed in this manner, it follows that it is highly contingent upon the actual history of science. In his 2007 paper Worrall says:

No one should claim a stronger sense of continuity, and hence a stronger version of realism, than is compatible with the historical record. We should look for the strongest such version and see if it is a continuity worth having. If there is no such notion of continuity worth having, then there is no sustainable version of realism. However, I hold that there is a continuity (admittedly of an approximate kind) at the structural level that is substantial enough to count and hence I hold that [structural scientific realism] is a sustainable version of scientific realism, and indeed... the only sustainable version. (2007, p. 144)

Poincaré enters the picture as being, in Worrall's view, the first figure to both present a version of the pessimistic meta-induction and to advocate a position similar to his own ESR. Worrall writes:

There was continuity or accumulation in the shift [from Fresnel's theory of light to Maxwell's], but the continuity is one of form or structure, not of content. In fact this claim was already made and defended by Poincaré. And Poincaré used 
the example of the switch from Fresnel to Maxwell to argue for a general sort of syntactic or structural realism ... This largely forgotten thesis of Poincaré's seems to me to offer the only hopeful way of both underwriting the 'no miracles' argument and accepting an accurate account of the extent of theory change in science. (Worrall 1989, p. 117; emphasis original)

This characterization of Poincaré as a historical precursor for contemporary ESR can be found elsewhere in the literature. For example, Zahar (2001, p. 37) agrees with Worrall in characterizing Poincaré as an epistemic structural realist:

Poincaré's structural realism is in a sense a reversal of Quine's slogan: to be is to be quantified over (in some first-order theory); for according to Poincaré, only the universals, and more particularly the relations occurring in a unified and empirically successful theory, mirror the ontological order of things. As for the nature of the relata, it will forever remain hidden from us.

Like Worrall, Gower (2000) designates Poincaré as one of the earliest adherents to structural realism, where Gower understands the term as follows (pp. 73-74):

In the case of 'structural' scientific realism, the central idea is that scientific theories do indeed provide information unavailable to us in observation and experimentation, but that information is about the form or structure, rather than the nature or content, of what is unobservable. Often, it is claimed, when one theory is replaced by another, it is information about the essential nature of what is unobservable that is replaced, rather than information about the structure of the unobservable.

In the very same paragraph quoted above, Gower goes on to state that "the idea of structural realism, broadly construed" had been adopted by Poincaré, Duhem, Cassirer, Schlick, Carnap, and Russell. Gower proceeds to give an account of how several of these historical figures, among others, can be considered as latching onto particular tenets of structural realism. He begins the section on Poincaré by claiming "The view we know as structural scientific realism was explicitly and clearly expressed by Poincaré" (Ibid., p. 80), a statement that is footnoted with references to the discussion of Poicnaré's position in Worrall's 1989 and 1994, to Psillos 1995, and to Zahar 1996.

After a brief sketch of Poincaré's view (supplemented with the usual quotes from Poincaré's major works), Gower concedes that though from a modern perspective one might easily find something like the no miracles argument and the pessimistic meta-induction in Poincaré, one must ask whether this modern characterization misrepresents his position; Gower notes in particular (cf. p. 101) the mind-dependent aspect of Poincaré's view (of which more below). In the end, though, Gower decides that the usual 'rough' characterization of Poincaré is generally correct, writing (Ibid., p. 86): "For both Poincaré and Duhem, 
then, a defensible scientific realism must be structural in the sense that it attributes reality to the relational structure of a scientific theory."

We think that there is widespread recognition that attributing ESR to Poincaré is a little "rough and ready". Our goal in this paper is to set out the epistemic, structuralist and realist character of Poincaré's position. Domski (2000) explicitly argues that Poincaré's position should not be interpreted as straightforwardly realist. We agree with her assessment, and will here explore Poincaré's structuralism with respect to the conventionalist and idealist aspects of his philosophy of science. Indeed, we shall argue that all three terms in the ESR classification of Poincaré's position ("epistemic", "structuralist", and "realist") should be handled with care: each means something rather different for Poincaré than for Worrall (and for contemporary ESR in general). Moreover, the motivation for Poincaré's position demands re-examination. We ask: is Worrall right that Poincaré argues for his structuralist position by appeal to history of science and the pessimistic meta-induction?

\section{Preliminary remarks on Poincaré's epistemology, structuralism and realism}

It will be helpful to begin by covering some commonly understood ground regarding Poincaré's epistemology, structuralism and realism. Below we provide a brief refresher on where Poincaré stands with respect to each.

There's no doubt about the appropriateness of labeling Poincaré's position as epistemic in some sense, for in all of his popular works he stresses that which is knowable. More specifically, he is concerned repeatedly with that which is knowable by us - with the particular faculties we have qua human beings. However, his focus on what we can know needs to be understood in the wider context of his epistemology, and this will be central theme of our paper. We return to it in section 5 below.

Turning now to Poincaré's structuralism, there are two aspects we want to highlight at the outset. First, Poincaré is clear that when doing science, our commitment is to relations rather than to the things in themselves. There is a famous statement to this effect in the preface of Science and Hypothesis (1902, p. xxiv; hereafter SH): "The aim of science is not things in themselves, as the dogmatists in their simplicity imagine, but the relations between things; outside those relations there is no reality knowable." Thus, there is an epistemic relationist aspect to Poincaré's structuralism.

Second, Poincaré's view of theory construction contains a distinct structuralist strain. He describes the role of mathematical physics within physics to be a structural one: in constructing a scientific theory we use mathematics to structure empirically-derived scientific facts. Writing about this in SH (p. 141) he says: "Science is built up of facts, as a house is built of stones; but an accumulation of facts is no more a science than a heap of stones is a house." Employing a different analogy, Poincaré compares the function of mathematical physics to that of a library catalogue, where the experimental facts serve as 
the "books" (Ibid., pp. 144-145). It is the duty of the mathematical physicist to take new data generated by experiment and order them usefully (where "usefully" means that this cataloguing process directs us toward the sorts of experiments necessary for supplementing the library with interesting new books). In short, facts must be given structure - this is what it is to do science, and to construct scientific theories.

Both these aspects of Poincaré's structuralism - his "epistemic relationism" and his "theories as structures" - will be important in what follows.

Lastly, consider Poincaré's realism. It is worth noting immediately that Poincaré distinguishes between "brute facts", or facts-in-the-world, and the facts that serve as the subject-matter of knowledge (and more specifically, of science). He explains in The Value of Science (1905, hereafter VS) that "The scientific fact is only the crude fact translated into a convenient language" (p. 120, emphasis original), and later, "[A]ll the scientist creates in a fact is the language in which he enunciates it" (Ibid., p. 121; emphasis original). Note that "scientific facts" according to Poincaré involve an ineliminable human contribution.

That said, Poincaré's popular writings are full of phrases such as "objective reality", "true relations", "real relations", and so on. Much of this talk sounds realist, at least about relations. In the very chapter of SH appealed to by Worrall for his arguments, Poincaré writes (p. 161): "The true relations between these real objects are the only reality we can attain." However, such statements concerning truth, reality and objectivity should not be given a straightforward realist interpretation, as Domski (2000) points out. To wit, consider the following excerpt from VS (p. 12):

If truth be the sole aim worth pursuing, may we hope to attain it? It may well be doubted. Readers of my little book 'Science and Hypothesis' already know what I think about the question. The truth we are permitted to glimpse is not altogether what most men call by that name.

What does Poincaré mean by "truth", then? Poincaré is explicit about how he should be understood. A few pages after the above quote from VS, he continues to say:

Does the harmony the human intelligence thinks it discovers in nature exist outside of this intelligence? No, beyond all doubt, a reality completely independent of the mind which conceives it, sees or feels it, is an impossibility. A world as exterior as that, even if it existed, would for us be forever inaccessible. But what we call objective reality is, in the last analysis, what is common to many thinking beings, and could be common to all; this common part, we shall see, can only be the harmony expressed by mathematical laws. It is this harmony then which is the sole objective reality, the only truth we can attain... (p. 14) 
As this quotation makes clear, knowledge of a mind-independent reality is, for Poincaré, impossible. Moreover, objectivity means inter-subjective agreement (between human beings, or beings with faculties "sufficiently similar" to our own), and truth is located within this same inter-subjective agreement. Scientific truth and objectivity are what is intersubjectively stable for creatures sufficiently like us; and since (as we have seen) mathematical laws express relations between scientific facts, "objective reality" refers to intersubjective agreement concerning these relations.

Similar remarks to those quoted above occur often in the body of Poincaré's works, and this is sufficient to warrant the conclusion that there is a strong idealist strain within his thought. Clearly, this has a bearing on both his epistemology and his realism. We pursue these issues further in our discussion below.

\section{Objectivity and structuralism}

In the preceding section we noted that for Poincaré, the idea of objectivity concerns intersubjective agreement. Related to this is Poincaré's account of objective knowledge more generally. In their book on objectivity, Daston and Galison (2007) claim that the grounds for Poincaré's structuralism lie in his account of objectivity. They distinguish this from the motivation of current structural realists, for which they cite the challenges posed to realism by underdetermination of theory by data and the pessimistic meta-induction. They write (p. 261):

Yet the preoccupations of the late twentieth-century structural realists were not those of the early twentieth-century structural objectivists: the former, like all realists, were primarily interesting in the justification for the claim that science was true, that it correctly described the real features of the world; the latter (including Poincaré) were chiefly concerned with the justification for the claim that science was objective, that it was "common to all thinking beings."

The reference here is to VS, and has been quoted in full above. According to Daston and Galison, the challenge to which Poincaré and others were responding arose from developments in mid nineteenth century physiology, psychology and ethnology that cast doubt on shared experience as the ground objectivity. The response was (p. 259) "not to reject scientific objectivity but to deepen it". We can see Poincaré responding to exactly this challenge in Chapter VI of VS, entitled "Objectivity of Science". First, he argues for the claim that (p. 345) "what is objective must be common to many minds and consequently transmissible from one to the other". Then, Poincaré argues that (p. 345):

Sensations are therefore intransmissible, or rather all that is pure quality in them is intransmissible and forever impenetrable. But it is not the same with relations between these sensations. From this point of view, all that is objective is devoid of all quality and is only pure relation... 
He argues for this by considering the case of color perception, and claiming that we have no means of verifying whether "the sensation I call red is the same as that which my neighbour calls red." This is an expression of the challenge to objectivity discussed by Daston and Galison. Poincaré concludes thus:

... we must nevertheless admit that nothing is objective which is not transmissible, and consequently that the relations between the sensations can alone have an objective value.

The argument for structuralism that Poincaré gives here can be put into premise/conclusion form as follows, with "communicable" substituted for "transmissible":

\section{Argument 1: The argument from objectivity}

- Objective knowledge is necessarily common to all (i.e., inter-subjectively stable).

- That which is common to all is necessarily communicable.

- That which is communicable is knowledge of relations only.

- Therefore, Objective knowledge just is knowledge of relations.

This is a very strong conclusion: all objective knowledge (not just scientific knowledge) is necessarily knowledge of relations. It rests on Poincaré's account of the relationship between objectivity and communicability (expressed in premises 1 and 2), and on the empirical discoveries stressed by Daston and Galison (on which premise 3 rests). Insofar as the restriction of knowledge to knowledge of relations is a form of epistemic structuralism, this argument supports such a version of epistemic realism.

We saw above that, according to Poincaré, scientific facts are placed into structures to create scientific theories - in other words, scientific theories "order the facts". This was one aspect of Poincaré's structuralism. Now we see that on Poincaré's view, our knowledge of the scientific facts is knowledge of relations; this is the second aspect of his structuralism alluded to above. Both aspects of his structuralism (that theories are structures and that facts are relational) are united by the view that all objective knowledge is necessarily knowledge of relations.

At this point we already see that Poincaré's structuralism is deeper and more thoroughgoing than that of the typical contemporary epistemic structural realist. Notice, though, that one could adopt Poicnaré's structuralist approach to scientific theories without also committing to his view that objective knowledge (including knowledge of scientific facts) just is knowledge of relations. We shall return to this point in section 8.2. 


\section{Poincaré's Kantian idealism}

We saw above in section 3 that there is a strong strain of idealism in Poincaré's philosophy of science. In this section we briefly review his philosophy of mathematics, and use this to say something more about how to understand the idealism in Poincaré's philosophy of mechanics and mathematical physics.

\subsection{Mathematics and the roles of a priori intuition}

Let us begin with arithmetic. Like Kant, Poincaré grounded arithmetic in synthetic a priori intuition. In SH (Part I, Ch. I), Poincaré argues that "indefinite repetition of the same act", and thus reasoning "by recurrence", is essential to arithmetical reasoning, allowing us to pass from particular results to general theorems. He argues that this rule of reasoning by recurrence is obtained neither from experience nor from logic (it does not follow from the principle of non-contradiction), but is an a priori synthetic intuition. He writes ( $\mathrm{SH}$, pp. 12-13): "This rule, inaccessible to analytical proof and to experiment, is the exact type of the a priori synthetic intuition." He goes on (p. 13): "The mind has a direct intuition of this power, and experiment can only be for it an opportunity of using it, and thereby of becoming conscious of it." In other words, through using the rule, we become aware that we have this intuition.

Poincaré also grounded geometry in a priori synthetic intuition, but here he made an important departure from Kant. In SH Poincaré constructs the mathematical continuum in two steps, each of which makes use of the arithmetical synthetic a priori intuition of "indefinite repetition of the same act" mentioned above. However, in Chapter III of Last Essays (1913, hereafter LE), Poincaré is explicit that we have an intuition of the spatial continuum that has the same status as our arithmetical intuition. He writes (LE, p. 44):

I shall conclude that there is in all of us an intuitive notion of the continuum of any number of dimensions whatever because we possess the capacity to construct a physical and mathematical continuum; and that this capacity exists in us before any experience because, without it, experience properly speaking would be impossible and would be reduced to brute sensations, unsuitable for any organization; and because this intuition is merely the awareness that we possess this faculty. And yet this faculty could be used in different ways; it could enable us to construct a space of four just as well as a space of three dimensions. It is the exterior world, it is experience which induces us to make use of it in one sense rather than in the other.

Poincaré maintains that metrical and projective properties are not part of the intuition that grounds our ability to construct space. Rather than a geometrical intuition (alongside the arithmetical), we have a more general spatial intuition. Thus, Poincaré differs from Kant in maintaining that the dimensionality of space is not synthetic a priori. Folina 
(1992) argues, successfully in our opinion, that this is because, according to Poincaré, "it is possible to construct viable empirical theories based upon the hypothesis that space is, for example, four-dimensional" (Folina 1992, p. 36), where "viable" means "viable for us". This connects directly with Poincaré's famous conventionalism concerning the axioms of physical geometry: when Poincaré says that "one geometry cannot be more true than another; it can only be more convenient" ( $\mathrm{SH}, \mathrm{p} .50$ ), this is because one need not use Euclidean geometry in order to describe the empirical world as we experience it.

In both mathematics and science, Poincaré was focused on what we can know-i.e., what is knowable by us, as finite beings, with our intuitive faculties. Folina argues that in the case of arithmetic, the significance of the synthetic a priori status is that we cannot build a "non-standard" arithmetic - or indeed any formal system - without these principles. Similary, she says, in the case of geometry, or rather spatial continuity, the significance is that any account of the world as we experience it will necessarily presuppose the continuity of space. She urges that the relationship of mathematics to experience is crucial to understanding Poincaré's philosophy of mathematics (Folina, p. 114):

Mathematics, like any science, must seek after truth. And truth means more than mere consistency. In mathematics it means (on the Poincaré view) that the axioms cohere with our intuitions, that is, with the form of experience.

This concludes our brief recapitulation of the role of intuition in Poincaré's philosophy of mathematics. We turn our attention now to empirical science.

\subsection{Empirical science and the roles of a priori intuition}

It is worth recalling before we begin that here, too, "truth" for Poincaré means intersubjective agreement concerning the world as we experience it. Both arithmetical and spatial intuition are indispensable for empirical science, and it is worthwhile exploring the roles that they play.

In the above quotation from LE (p. 44), Poincaré states that the very possibility of our experience of the world as containing empirical objects depends upon spatial intuition when he writes, "this capacity exists in us before any experience because, without it, experience properly speaking would be impossible and would be reduced to brute sensations, unsuitable for any organization." In other words, spatial intuition is that through which our sensations are constituted into our experiences of physical objects; objects which endure through space and time.

Moreover, the role of a priori intuition in empirical science extends beyond this, or so we shall argue. This is because a science of empirical objects goes beyond mere experience of objects: we must form generalizations over these objects, and our ability to form these generalizations is itself grounded in a priori intuition. In SH (Part I, Ch. II), Poincaré asserts that the business of science concerns generalizations - to move from premises to conclusions that are "in a sense more general than the premisses" (p. 4). His position may 
be summed up by his own slogan: "There is no science but the science of the general" (Ibid., p. 4). Granting this, we can ask first about the nature of this generalization, and then about what grounds our ability to form such generalizations.

Poincaré distinguishes between mathematics and the physical sciences in the following relevant respect. He highlights the similarity between (i) reasoning by recurrence in arithmetic and (ii) induction in physical science, and then points out that induction in the physical sciences is uncertain, whereas reasoning by recurrence is not (see $\mathrm{SH}, \mathrm{p}$. 13). The reason he gives is that induction depends for its success on "an order which is external to us" whereas proof by recurrence depends for its success on "a property of the mind itself". Poincaré's own writings leave us at this point of distinguishing between the nature of the generalizations found in mathematics and the physical sciences. But with this difference noted, we might still want to ask what grounds our ability to perform inductive reasoning in the physical sciences. We have seen that in mathematics our ability to generalize is grounded in arithmetical intuition. What about the physical sciences? In answering this, it seems to us that a plausible case can be made for three further roles for a priori intuition within Poincaré's philosophy of science.

Consider first the following quotation from Folina. She begins with the role of spatial intuition with respect to our experience of physical objects, and then moves on to consider generalizations:

A priori intuition - or the form of experience - is that via which we understand, by our sensory manifold, an experience of a single object enduring through space and time, despite the inevitably incomplete character of experience. It is also that via which we understand certain rules as characterizing infinite, yet determinate, collections. A priori intuition can thus be regarded as a 'glossing over' faculty: a faculty which glosses over the incomplete character of both empirical and mathematical experience. It is a procedure whereby we ignore all the elements which could be generated by a rule, and we disregard or 'smooth out' the disparate character of perception. (p. 86)

Folina argues that for Poincaré our ability to "gloss over" - and thereby to make generalizations - lies in a priori intuition (in spatial intuition for empirical generalizations, and in arithmetical intuition for mathematical generalizations). The point here is that in order to form generalizations we must disregard as irrelevant certain features of the particular objects that we are placing under the generalization. In the case of physical objects it is, according to Folina's reading of Poincaré, our spatial intuition that allows us to do this.

The second place where a priori intuition plays a role is as follows. Disregarding certain features as irrelevant is necessary but not sufficient for us to form a generalization: we require also the concept of indefinite iterability (a concept that, for example, allows us to repeatedly apply rules). As Folina writes (Ibid., p. 93): 
Poincaré believed that the concept of indefinite iterability... is foundational, not only for arithmetic, but for all systematic thinking; and its epistemological source is synthetic a priori intuition. ...[I]t underlies all systematic thinking because it underlies our ability to generalize.

In short, our ability to generalize is grounded in arithmetical a priori intuition, because this intuition grounds our ability to perform iterations. Thus, arithmetical intuition also plays a crucial role in our ability to generalize with respect to empirical objects.

We will come to the third role for a priori intuition shortly, but first - with the above point in mind - we can return to where Poincaré left us, with the distinction between mathematical reasoning by recurrence and induction in the physical sciences. We saw that the difference lies in the objects that are the subject-matter of the generalization. The fallibility of induction lies in the fact that we can make mistakes when we decide which aspects of the particular physical objects to ignore as irrelevant, and which to take into account when forming the generalization. Nevertheless, with this decision made, what grounds our ability to form the generalization is the same in the case of induction as it is for mathematical reasoning by recurrence: it is arithmetical a priori intuition. This is not something that Poincaré says, but it is, we maintain, a plausible answer to a question that he left unanswered. Furthermore, it is supported by the discussion that Poincaré does offer regarding generalization in physical science.

Generalization is involved in physical science at two distinct stages. The first is when the empirical data are organized: we must draw our line through the dots on the page that record our experimental results. The relevant point for our purposes is that this choice goes beyond "mere" generalization (SH, pp. 142-143):

However timid we may be, there must be interpolation. Experiment only gives us a certain number of isolated points. They must be connected by a continuous line, and this is a true generalisation. But more is done. The curve thus traced will pass between and near the points observed; it will not pass through the points themselves. Thus we are not restricted to generalising our experiment, we correct it... Detached facts cannot therefore satisfy us, and that is why our science must be ordered, or better still, generalised.

Thus the interpolation - the act of drawing a curve to fit the data - is a moment in which Poincaré claims we not only generalize the data, but also correct it. This additional feature of empirical generalization (beyond that found in mathematics) arises from the different nature of objects that serve as subject-matter for the generalizations, and leads to the fallibility of those generalizations.

The second type of generalization takes the results of this first stage (drawing curves through data points) as input in order to generate empirical laws. Thus, the laws are grounded from the start on generalizations. It is these laws, then, that enable us to achieve 
the desired generality that the human mind seeks (see VS, p. 14, quoted above), and which allow us to progress in science. As Poincaré says (SH pp. 129-130):

Who gives us the right of attributing to the principle itself more generality and more precision than to the experiments which have served to demonstrate it? This is asking, if it is legitimate to generalise, as we do every day, empiric data... One thing alone is certain. If this permission were refused to us, science could not exist; or at least would be reduced to a kind of inventory, to the ascertaining of isolated facts. It would not [sic] longer be to us of any value, since it could not satisfy our need of order and harmony, and because it would be at the same time incapable of prediction.

In sum, it seems to us that a priori intuition clearly grounds our ability to construct the generalizations that form the very substance of physical theorizing.

There is a third role for a priori intuition. It is not just our ability to construct generalizations that is grounded in a priori intuition: our ability to apply the resulting generalizations is similarly grounded. With respect to mathematics, Folina writes (1992, p. 87):

In order to understand the abstract characterization of a rule, we must understand an arbitrary instance of it. ... Applying a rule requires that we see that the application possesses the same essential structural properties, or 'shape', as the arbitrary instance given in the schematic characterization of the rule. The aspects which are structural are those which an arbitrary instance possesses. A priori intuition supplies us with the ability to understand what these are.

If this reading of Poincaré is correct, then the conclusion is readily extended beyond mathematics. A physical law is a particular type of rule, and it is a generalization. In order to apply laws (generalizations) to physical objects we must be able to recognize that the objects instantiate the law. We might go further, and insist that to understand a physical law is to be able to recognize an instance of that law. The point is this: insofar as our ability to recognize physical objects as instantiating of a law depends on arithmetical and/or spatial intuition, there is this further role for a priori intuition in Poincaré's philosophy of science.

As Folina emphasizes, the generalizations in play here are structural generalizations. That this must be the case follows from her account of a priori intuition. There is, moreover, an additional way to see that the type of generalization at work in physical science must be structural. We have seen that laws for Poincaré capture the relations between things; thus, to recognize that objects offer an instance of a given law is to recognize that they stand in the relations that are described by the law. In order to achieve this, we must ignore the non-relational features of the objects, if any such are presented to us in experience. A priori intuition is therefore not only that which enables us to generalize, but also that which 
enables us to apply the resulting generalizations. By the very nature of what is involved in the construction and application of generalizations, they must concern relations: they are what we will call structural generalizations.

In this section we have discussed the role of Kantian idealism in Poincaré's philosophy of science. This idealism is a central characteristic of both his epistemology and his realism. Therefore, when classifying Poincaré as an epistemic structural realist we must read both the "epistemic" and "realist" terms of this classification in that light. As we shall now argue, Poincaré's structuralism, too, is directly informed by his idealism.

\section{Generalization and structuralism}

We saw in earlier sections that there are two strands of structuralism in Poincaré's writing: one associated with his claim that relations are all that we can know (his "epistemic relationism"), and the other being his claim that scientific theories just are structures we impose on the facts. We have also shown (cf. section 4) that Poincaré argues for the former (concerning structure qua relations between things) on the basis of his account of objective knowledge. Our considerations of Poincaré's Kantian idealism lead to an argument for the latter (concerning structure qua theories), as follows.

\section{Argument 2: The argument from generalization}

- Scientific laws are our generalizations.

- We are able to generalize due to our arithmetical a priori synthetic intuition.

- In particular, arithmetical intuition enables us to form structural generalizations.

- Therefore, Scientific laws are structural generalizations.

So far as we are aware, Poincaré never states this argument explicitly. However, he is explicitly committed to the first premise, as various statements in $\mathrm{SH}$ make plain. On p. 110 he declares that certain laws are conventions, and as we demonstrate in the next section, convention involves generalization. Thus, laws involve generalizations inasmuch as those laws are considered conventions. On pp. 129-130 of SH, Poincaré (discussing the two fundamental "principles" or laws of thermodynamics) asks:

...who gives us the right of attributing to the principle itself more generality and more precision than to the experiments which have served to demonstrate it? This is asking, if it is legitimate to generalise, as we do every day, empiric data, and I shall not be so foolhardy as to discuss this question, after so many philosophers have vainly tried to solve it. One thing alone is certain. If this 
permission [to generalize] were refused to us, science could not exist; or at least would be reduced to a kind of inventory, to the ascertaining of isolated facts.

Poincaré goes on in chapter 9 to say "It is not sufficient merely to observe; we must use our observations, and for that purpose we must generalise" (p. 140), and to define what a good experiment is: "It is that which teaches us something more than an isolated fact. It is that which enables us to predict, and to generalise. Without generalisation, prediction is impossible" (p. 142). A good experiment, in other words, allows us to translate particular instances into laws by generalizing those instances. And in this way, laws are themselves generalizations.

Our discussion of Poincaré's Kantian idealism shows that it is at least plausible that Poincaré is committed to the remaining premises (cf. section 5.2 above). Given these, the conclusion follows readily. Thus, it turns out that Poincaré has the resources to formulate an argument for his claim that scientific laws are structures imposed on the facts, and therefore for this second strand of his structuralism as well.

The upshot of these remarks on generalization, when taken together with the results of the preceding sections, is that all three features of the characterization of Poincare as an epistemic structural realist must be understood as being informed by his Kantian idealism. This makes Poincaré's version of ESR distinct on all three counts from that found in today's philosophy of science literature.

\section{Poincaré's conventionalism}

Perhaps an obvious place to challenge the interpretation of Poincaré as a scientific realist is through the most famous aspect of his philosophy of science: his conventionalism. However, the focus of most discussion on this point is conventionalism in philosophy of geometry specifically, and it is perhaps less obvious that his conventionalism pervades his account of mechanics and physical science as well. In this section, we argue that Poincaré's conventionalism extends into mechanics and physics, and that this fact (along with his Kantian idealism) demands that we read the "realist" classification of his structuralism with care. Let us begin, though, with a very brief review of his geometric conventionalism.

\subsection{The axioms of geometry as convention}

Poincaré's conventionality with respect to geometry is widely known. Concisely, Poincaré's argument involves reasoning by elimination: he asks, what sort of science is geometry? Can it be considered an a priori science, as Kant insisted? Poincaré answers in the negative, arguing against Kant in part by discussing the equal 'conceivability' of non-Euclidean geometries, and in part by appealing to the indemonstrable axioms that define them ( $\mathrm{SH}$, p. 35: "Every deductive science, and geometry in particular, must rest upon a certain number of indemonstrable axioms."). Poincaré argues that the axioms of other geometries 
of constant curvature - namely that of Lobatschevsky and of Riemann - are not logically contradictory to Euclidean geometry and therefore cannot be ruled out a priori. Thus we are left in a state of underdetermination, which is in contradiction with the Kantian claim for the a prioricity of Euclidean geometry.

Can geometry be considered an empirical science, then? The answer here is again negative, and Poincaré gives two reasons: first, he asserts that geometry (unlike any empirical science) cannot be modified or revised in light of new experiments, and second, geometry is exact and does not rely on approximations, as empirical sciences are constrained to do. If geometry can be considered neither an empirical nor an a priori science, all that remains is that it be situated on some middle ground. This middle ground is convention:

The geometrical axioms are therefore neither synthetic a priori intuitions nor experimental facts. They are conventions. Our choice among all possible conventions is guided by experimental facts; but it remains free, and is only limited by the necessity of avoiding every contraction, and thus it is that postulates may remain rigorously true even when the experimental laws which have determined their adoption are only approximate. In other words, the axioms of geometry ... are only definitions in disguise. (SH, p. 50; emphasis original)

\subsection{Convention in mechanics and physics}

Already in the Author's Preface to SH (p. xxvi) — after stating that he will argue for the conventional nature of geometry's axioms - Poincaré continues to say:

In mechanics we shall be led to analogous conclusions, and we shall see that the principles of this science, although more directly based on experience, still share the conventional character of the geometrical postulates.

This is a clear statement that his conventionalism extends into mechanics, at least. Poincaré states that the principles of mechanics appear to us under two different aspects (SH, pp. 135-136):

On the one hand, there are truths founded on experiment, and verified approximately as far as almost isolated systems are concerned; on the other hand, there are postulates applicable to the whole of the universe and regarded as rigorously true.

It is this second aspect under which we realize that principles are nothing more than convention.

Principles are conventions and definitions in disguise. They are, however, deduced from experimental laws, and these laws have, so to speak, been erected into principles to which our mind attributes an absolute value. (SH, p. 138) 
He goes on to explain the process of elevating laws to the statues of principles as such:

How can a law become a principle [convention]? It expressed a relation between to real terms, A and B; but it was not rigorously true, it was only approximate. We introduce arbitrarily an intermediate term, C, more or less imaginary, and $\mathrm{C}$ is by definition that which has with A exactly the relation expressed by the law. So our law is decomposed into an absolute and rigorous principle which expresses the relation of $\mathrm{A}$ to $\mathrm{C}$, and an approximate experimental and revisable law which expresses the relation of $\mathrm{C}$ to $\mathrm{B}$. But it is clear that however far this decomposition may be carried, laws will always remain. (SH pp. 138-139, emphasis original)

Poincaré supports this claim with an argument analogous to the one made for the axioms of geometry. Principles are not a priori because we arrive at them via empirical investigation. Yet they are not empirical claims either: though originally derived from experiment, we elevate them to a status that no longer admits of empirical verification or falsification. Poincaré writes (SH, p. 136):

If these postulates possess a generality and a certainty which falsify the experimental truths from which they were deduced, it is because they reduce in final analysis to a simple convention that we have a right to make, because we are certain beforehand that no experiment can contradict it.

Among the principles are, for example, Newton's three laws of motion and energy conservation. Yet (recall from section 4) that an important difference remains between geometry and mechanics owing to our fallibility in treating the subject-matter of each science. Again from SH (p. 137):

Our fundamental experiments [in geometry] are pre-eminently physiological experiments which refer, not to the space which is the object that geometry must study, but to our body - that is to say, to the instrument which we use for that study. On the other hand, the fundamental conventions of mechanics and the experiments which prove to us that they are convenient, certainly refer to the same objects or to analogous objects. Conventional and general principles are the natural and direct generalisations of experimental and particular principles.

As we saw above, the objects of mechanics are distinct from the objects of geometry, and because they have a mind-independent component, we are subject to error when we perform generalizations over them. That is, we could choose to ignore or include data that will lead us to make a generalization that will later turn out to be inconvenient. So while the axioms of geometry are unrevisable on Poincaré's view (for there is no possibility that we could change our mind about what constitutes the most convenient geometry), 
the axioms of mechanics are revisable on the basis of convenience with respect to future empirical evidence.

With this difference noted, it is nevertheless the case that a conventionality analogous to that associated with the axioms of geometry also applies to the principles of mechanics. The question facing the scientific realist is this: how, then, can these "conventions" of Poincaré's - the principles of mechanics - express real relations between things?

Poincaré himself insists (cf. the above quote from SH, pp. 138-139) that what conventions express are the relations between a real thing ("A" or "B") and an idealized thing ("C"), so they alone cannot express relations between two real things. That relational work is done by convention with the addition of laws. Therefore, in committing ourselves to the structure of a scientific theory (consisting of conventions plus empirical laws) and to its expression of relations between real things, we are on both counts inserting a conventional element into our "structural realism".

Might one limit this conventional element to mechanics, and insist that all laws associated with other natural sciences beyond simple mechanics remain empirical laws, not to be elevated to the status of principles? This may indeed have been Poincaré's view. It seems to us, however, that it is difficult to make a robust distinction here between mechanics and other areas of mathematical physics: for example, which is the nature of the second law of thermodynamics? Unless a robust distinction can be made that shows how and why the principles of mechanics are conventional, whereas the laws appearing elsewhere in mathematical physics are not, the conventional element will pervade all of mathematical physics. Either way one chooses to interpret Poincaré, his conventionalism renders his particular brand of realism distinct from that associated with today's ESR.

\section{Three arguments for structuralism}

In reconsidering Poincaré's philosophy of science we have come across two arguments for structural realism (see sections 4 and 6). What of Worrall's argument, which he attributes to Poincaré? And how do these three arguments compare?

\subsection{Structuralism and the "bankruptcy of science"}

Recall from section 2 that Worrall (1989) uses the pessimistic meta-induction to motivate his ESR: in order to avoid the anti-realist thrust of the pessimistic meta-induction, Worrall urges a retreat from standard scientific realism to structural realism, whereby we commit ourselves to only the structural part of our theory and remain agnostic as to the natures of the entities in the world instantiating those structures. Worrall (Ibid., p. 149) points to the Preface and Chapter 10 of SH to argue that Poincaré both confronts the pessimistic meta-induction (or the "bankruptcy of science" in Poincaré's own terminology) and rejects it via his structuralism concerning scientific theories. 
The "bankruptcy of science" thesis is stated by Poincaré as follows (SH, p. 160; emphasis original):

The ephemeral nature of scientific theories takes by surprise the man of the world. Their brief period of prosperity ended, he sees them abandoned one after another; he sees ruins piled upon ruins; he predicts that the theories in fashion today will in a short time succumb in their turn, and he concludes that they are absolutely in vain. This is what he calls the bankruptcy of science.

The structuralist exit is stated thus:

The true relations between these real objects are the only reality we can attain, and the sole condition is that the same relations shall exist between these objects as between the images we are forced to put in their place. If the relations are known to us, what does it matter if we think it convenient to replace one image by another? In the case of contradiction [between two theories] one of them at least should be considered false. But this is no longer the case if we only seek in them what should be sought. It is quite possible that they both express true relations, and that the contradictions only exist in the images we have formed to ourselves of reality. (SH, pp. 161, 163)

In other words, theories that contradict one another at the level of the images associated with them may be found to agree once we restrict our attention to the relations expressed by the theories. It is this observation (incorporated within Poincaré's epistemic relationismcf. section 3) that Poincaré puts to work in his rejection of the "bankruptcy of science". By focusing on the relations instead of troublesome entity-talk, one can tell a continuous (and progressive) story about the history of scientific theories. Poincare stresses that while the entities may change in the transition from one theory to the next, the form of the old theory is preserved: "Our equations become, it is true, more and more complicated... but nothing is changed in the relations which enable these equations to be derived from each other" (SH, p. 181). A successful theory is not one that necessarily gets the entities right-indeed, Poincaré is dubious that the truth of such claims can be evaluated at all!- - but instead, a successful theory is one that correctly describes observed relations and fails to affirm false ones. The very best theories are those throwing into relief the greatest number of known relations and thereby exhibiting "traces of definitive construction" (SH, p. 175).

What is the relationship between the "bankruptcy of science" and Poincaré's structuralism? The standard interpretation, stemming from Worrall, is that the pessimistic metainduction is a motivation for Poincaré's structuralism. If this is correct, then Poincaré's position might similarly be understood as a retreat from scientific realism in the face of the pessimistic meta-induction, and might justly be thought of as a historical forerunner to Worrall's epistemic structuralism. 
It seems to us, however, that the inference in Poincaré is from his epistemic structuralism, independently grounded, to the rejection of the bankruptcy of science (rather than the other way around, as in Worrall's arguments). This claim is supported by the structure of Poincaré's argument, as set out in SH. In this text, Poincaré is developing an epistemology of science that begins with arithmetic and geometry and goes on to explain the role of mathematical physics in the natural sciences. As we have discussed here, his central concerns are the status of arithmetic and geometry, and of objective knowledge, as those issues were understood at the turn of the century, and his solutions are rooted in his Kantian epistemology. He is not primarily concerned with defending empirical science from antirealist arguments in the form of the pessimistic meta-induction. In fact, it seems instead that after developing his position, Poincaré then considers the bankruptcy of science to be trivially answered by his very position, in the manner of a corollary. Poincaré's discussion of the "bankruptcy of science" and its rejection by appeal to epistemic structuralism occurs in the tenth chapter (of thirteen) in $\mathrm{SH}$, after Poincaré has already introduced, motivated, and elaborated his structuralist position. In short, we believe we have demonstrated above that the pessimistic meta-induction plays a much smaller role in Poincaré's overall considerations than is commonly believed, and little if any in the fundamental motivations for Poincaré's epistemic structuralism (cf. sections 3 and 5 above). This is not to say that one cannot use Poincaré's ideas to construct Worrall's argument for epistemic structuralism (and even ESR) - surely one can. The point is simply that this is not how Poincaré himself went about arguing for his position.

\subsection{The three arguments compared}

On Worrall's account, the grounds for epistemic modesty rest on an argument from history: as a matter of historical fact (so the claim goes) it has turned out that science has seen a series of ontological discontinuities concerning the natures of the entities posited within theories. There is nothing in the argument for ESR that warrants the claim that the development of science had to go this way, nor that it must continue to show such ontological discontinuities. ESR is thus consistent with a future in which the ontology of our best theories has been stable for such a long time that the pessimistic meta-induction loses its force, and epistemic immodesty begins to regain its plausibility. In sum, the commitment to ESR is contingent upon the history of science.

By contrast, neither the argument from objectivity nor the argument from generalization is historically contingent. The former argument rests on a specific claim about the nature of objective knowledge. The latter argument rests on Poincaré's epistemologyspecifically, his account of a priori intuition and its role in grounding our ability to generalize.

As we noted above, the conclusion of the argument from objectivity ("Objective knowledge just is knowledge of relations") extends beyond scientific theories to objects of knowledge in general, including scientific facts. These too, according to Poincaré, are relational. 
The conclusion of this argument is therefore much stronger than is argued for by contemporary advocates of ESR.

Unlike the argument from objectivity, the argument from generalization is specific to scientific theories. In addition, it is worth noting that one could endorse this latter argument - and the conclusion that scientific theories are structures - without endorsing Poincaré's own view that the scientific facts are themselves relational. The conclusion of the argument from generalization is that the generalizations constructed on the basis of the scientific facts (whatever the nature of these facts may be) must be structural. One might think that there are non-structural aspects to "the facts" (or at least to some of the facts). One might also think that scientific theorizing could go astray if, when we generalize over the facts, we inadvertently "boost" non-structural aspects associated with the facts up into the theories. According to the argument from generalization, such "boosting" of non-structural aspects is illegitimate. Why? Because our ability to generalize is grounded in a priori intuition, and the generalizations that a priori intuition warrants are of a structural nature. The appearance in our generalizations of any non-structural features of the fact must thereby be considered epistemically unwarranted.

\section{Conclusions}

We conclude with some comparisons between Poincaré's position and the ESR championed by Worrall. Worrall's position can be encapsulated by the thesis that we have good reason to believe that the entities in the world exemplify the structures posited by our best scientific theories, but we should be non-committal about the non-structural natures of the entities in question. Poincaré's position can be understood as endorsing a stronger thesis in three respects. His position includes the claim that all objective knowledge, including all scientific knowledge, is necessarily knowledge of relations. Thus, (1) not just our scientific theories, but also the facts from which they are derived should be understood structurally, and (2) no "non-structural" objective knowledge is possible. This is part of the argument from objectivity. Finally, theories are structures: our ability to construct them is grounded in a priori intuition. Thus, (3) a structuralist approach to scientific theories does not follow from a choice we make to be epistemically modest in the face of history, but from what is epistemically warranted given our nature as knowers.

Our primary goal in this paper has been to clarify the ways in which Poincaré's structuralism differs from current ESR. We have seen that his epistemology is strongly influenced by Kant, and that his realism must also be understood in this light. Furthermore, where our theories contain principles they also contain an element of convention, and Poincaré cashes out what is "real" in terms of what is inter-subjective; both of these features of his philosophy bear on the "realist" characterization of his position. What one says about these issues, along with the "stronger" aspects mentioned above, will affect whether one interprets Poincaré as offering a form of ESR or not. In any case, it is clear that his position 
differs in interesting ways from current versions of ESR.

In our discussion of Poincaré's philosophy of science we have come across three arguments for structuralism. The first of these - Worrall's argument for ESR - is historically contingent. The other two are principled rather than being contingent upon the history of science. While current ESR is motivated primarily by the desire to overcome the pessimistic meta-induction, the latter two arguments may perhaps offer alternative ways to think about structuralism within philosophy of science.

\section{Acknowledgments}

Our thanks to Mary Domski, Janet Folina and Elaine Landry, and to those present at Paris, Macalester, and the Structuralism in Physics grad seminar at ND (Fall 2008), where earlier versions of this work were presented. This research was supported by the NSF (grant number SES-0724383 Brading 201201).

\section{References}

Daston, L. and Galison, P. (2007). Objectivity. New York: Zone Books.

Domski, M.A. (2000). The Epistemological Foundations of Structural Realism?: Poincaré and the Structure of Relations. Originally presented at University of Leeds Informal Seminar, 19 May 2000. Obtained from the author via private correspondence.

Folina, J. (1992). Poincaré and the Philosophy of Mathematics. New York: St. Martin's Press.

Gower, B. (2000). Cassirer, Schlick and 'Structural' Realism: the philosophy of the exact sciences in the background to early logical empiricism. British Journal for the History of Philosophy 8(1): 71-106.

Poincaré, H. (1902). Science and Hypothesis. Repr. New York: Dover, 1952. All page references are to this edition.

Poincaré, H. (1905). The Value of Science. Repr. New York: Dover, 1958. All page references are to this edition.

Poincaré, H. (1913). Last Essays. Repr. New York: Dover, 1963. All page references are to this edition. 
Psillos, S. (1995). Is structural realism the best of both worlds? Dialectica 49: 15-46.

Worrall, J. (1989). Structural Realism: The Best of Both Worlds? Dialectica 43: 99-124.

Worrall, J. (1994). How to Remain (Reasonably) Optimistic: Scientific Realism and the "Luminiferous Ether". In D. Hull, M. Forbes and M. Burian (eds), PSA 1994, Vol. 1. East Lansing: PSA. 334-342.

Worrall, J. (2007). Miracles and Models: Why reports of the death of Structural Realism may be exaggerated. Royal Institute of Philosophy Supplement 82: 125-154.

Zahar, E. (1996). Poincaré's structural realism and his logic of discovery. In J.L. Greffe, G. Heinzmann and K. Lorenz (eds) Henri Poincaré: Science and Philosophy, International Congress Nancy, France, 1994. Paris and Berlin, A. Blanchard and Akademie Verlag, 4568.

Zahar, E. (2001). Poincaré's Philosophy: From Conventionalism to Phenomenology, including an appendix co-authored with Worrall. Chicago: Carus Publishing. 